ARTICULO

Revista Derecho - Año 2 edición 3: 157 - 180

Web: http://www.revistaderecho.pe E-mail: editorial@revistaderecho.pe

ISSN 2313-6944

\title{
ESTUDIO DEL DEBIDO PROCEDIMIENTO EN LOS PROCESOS ADMINISTRATIVOS DISCIPLINARIOS RESPECTO A LOS DERECHOS DE LOS ADMINIS- TRADOS EN LA DIRECCIÓN REGIONAL DE EDU- CACIÓN PUNO EN EL AÑO 2014
}

INFORMACIÓN DEL ARTICULO

Art. Recibido: 12/01/16

Art. Aceptado: 06/06/16

Art. Publicado: $18 / 12 / 18$

PALABRAS CLAVE:

Administración Pública

lus Puniedi

Régimen Disciplinario

Proceso Administrativo

Disciplinario

Debido Procedimiento

Principios del Procedimiento

Administrativo Disciplinario

Derechos de los Administrados

Acción de Amparo

Wilfredo Flores Espillico*

\section{RESUMEN}

La presente investigación corresponde a una de enfoque Mixto con predominio cuantitativo. La potestad sancionadora de la Administración Pública debe respetar el Debido Proceso y los principios que informan la potestad sancionatoria del Estado, sin embargo el Debido Proceso presenta problemas no de orden sustantivo sino de aplicación práctica en cada proceso en particular, a ello no es ajena la justicia administrativa que se imparte dentro de la Administración Pública; en el caso concreto de los docentes y directores de los Institutos Superiores Públicos no universitarios que laboran en la Dirección Regional de Educación Puno bajo el régimen del Decreto Legislativo $\mathrm{N}^{\circ} 276$ y que durante el año 2014 hayan sido sancionados por la comisión de alguna falta administrativa, se realiza el presente estudio a fin de verificar si se ha considerado el Debido Procedimiento y además establecer si los derechos de los administrados han sido respetados o por el contrario hayan resultado lesionados por actuaciones arbitrarias de la Administración Pública, por lo que nuestro objetivo es: Determinar si en los procesos administrativos disciplinarios, concluidos en el año 2014, realizados por la Comisión Permanente de Procesos Administrativos de la DREP se respetó o no el Debido Procedimiento y se consideraron los principios del Derecho Administrativo Disciplinario. Luego de haber realizado la presente investigación y conforme nuestro objetivo planteado, llegamos a la conclusión que en los procesos administrativos disciplinarios realizados por la CPPA de la DREP concluidos el año 2014, no se respetó el Debido Procedimiento y asi como

Abogado, egresado de la Escuela Profesional de Derecho de la Facultad de Ciencias Jurídicas y Políticas de la Universidad Nacional del Altiplano. 


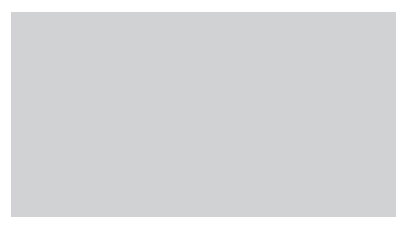

tampoco se consideraron los principios del Derecho Administrativo Disciplinario; el expediente disciplinario analizado se encuentran con afectación de derechos constitucionales de los administrados, debido a la escasa preparación que tienen los miembros que conforman la CPPA, lo cual ha sido percibido por los propios administrados.

\section{STUDY OF THE DUE PROCESS IN ADMINISTRATIVE DISCIPLINARY PROCESSES IN RELATION TO THE RESPECT OF RIGHTS OF THE ADMINISTERED AT THE REGIONAL EDUCATION OFFICE PUNO - 2014.}

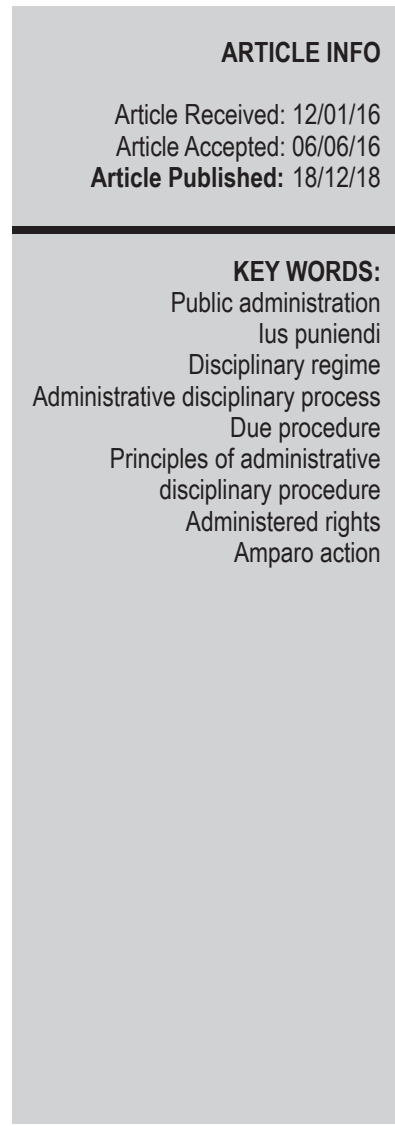

ABSTRACT

The present research corresponds to a mixed approach with quantitative predominance. The sanctioning powers of the Public Administration must respect the due process and the principles that inform the sanctioning power of the state; however, the due process presents non substantive problems but practical application in each process in particular, including the administrative justice that takes place within the public administration; in the specific case of teachers and directors of the public institutes who work in the Regional Education Office of Puno under the regime of the Legislative Decree No 276, in this case, during the year 2004 they were sanctioned by committing administrative offenses. The present study is aiming to verify whether the due process has been considered respecting the rights of the administered, or on the contrary whether they have been transgressed by arbitrary actions of the Public Administration, our main objective is: to determine whether the administrative and disciplinary processes concluded in the year 2014 carried out by the Permanent Commission of Administrative Processes at the DREP respected or not the due process and whether they considered the principles of administrative disciplinary law. After having performed the present research we arrived to the conclusion that the administrative and disciplinary processes undertaken by the CPPA at the DREP finished the year 2014, did not respect the due process and did not consider the principles of administrative disciplinary law; the findings of the disciplinary file case analyzed showed infringement of constitutional rights of the administered, due to the poor preparation of the CPPA members which has been perceived by the administered itself. 


\section{INTRODUCCIÓN}

El Estado peruano se proclama como un Estado Constitucional de Derecho, con clara vocación democrática, respeto a la supremacía constitucional y prioridad en la protección de los derechos fundamentales, en este contexto el Estado tiene la facultad de aplicar una pena o sanción a aquellas conductas contrarias a las leyes; esta es la facultad punitiva del Estado concebido como el ius puniendi, potestad del Estado "en virtud de la cual ésta, revestida de un poderío o imperio, declara punible determinados comportamientos que por su gravedad atentan contra la convivencia comunitaria y les impone penas y/o medidas de seguridad a título de consecuencia jurídica" (Velásquez citado en Villa Stein, 1998, p. 93).

Esta facultad de sancionar se manifiesta mediante dos vías, por un lado mediante el Derecho Penal, el cual interviene únicamente ante aquellas conductas de mayor disvalor, y por otro lado a través del Derecho Administrativo Sancionador -que comprende el Derecho Administrativo Disciplinario-, aplicable a conductas que lesionan el ámbito de la Administración e impone sanciones administrativas. Al respecto "El Derecho Disciplinario, en tanto franja específica del Derecho Administrativo Sancionador, tiene entre sus objetivos corregir y optimizar el desempeño de los funcionarios y servidores públicos, de modo que el servicio a los destinatarios sea de calidad y no se vea perjudicado o desnaturalizado por acciones u omisiones que quebrantan el profesionalismo y la eficacia en el cumplimiento de los deberes $y$, por lo mismo, busca también evitar la incidencia en ámbitos de incompatibilidades y prohibiciones". (Rojas, 2012, p. 758)

El ejercicio de la potestad disciplinaria obliga a la Administración Pública a respetar el Debido Proceso y los principios que informan la potestad sancionatoria del Estado. Empero, el problema del Debido Proceso no es de orden sustantivo, en cuanto a su comprensión doctrinal, sino básicamente de aplicación práctica en cada proceso en particular, a ello no es ajena la justicia administrativa que se imparte en la Administración Pública. En el caso concreto de los docentes y directores de los Institutos Superiores Públicos no universitarios que laboran en la Dirección Regional de Educación Puno y que durante el año 2014, bajo el régimen del Decreto Legislativo $\mathrm{N}^{\circ} 276$, hayan sido sancionados por la comisión de alguna falta administrativa, se hace necesario realizar un estudio de cómo se han realizado estos procesos disciplinarios a fin de verificar si los mismos se efectuaron en forma objetiva, si se ha considerado el Debido Procedimiento y además establecer si los derechos de los administrados han sido respetados o por el contrario hayan resultado lesionados por actuaciones arbitrarias de la Administración Pública en el ejercicio del ius puniendi.

Por lo que nuestro planteamiento del problema es el siguiente: ¿se respetó el Debido Procedimiento en 
los procesos administrativos disciplinarios realizados contra el personal docente y directores de los Institutos Superiores Públicos no universitarios de la Dirección Regional de Educación de Puno en el año 2014?.

La presente investigación se justifica en verificar si el Debido Procedimiento es considerado en los procesos disciplinarios realizados bajo el régimen del Decreto Legislativo 276 como garantía de respeto de los derechos de los administrados, para lo cual se ha desarrollado estructuralmente los conceptos básicos sobre la potestad disciplinaria de la Administración Pública y el Debido Procedimiento, describiendo los procedimientos y principios que lo rigen, de esta manera se pretende también brindar una herramienta didactica para que los servidores y funcionarios publicos conozcan los distintos aspectos que comprende el procedimento administrativo disciplinario y las garantias que los asisten como administrados.

\section{MATERIALES Y MÉTODOS}

El presente estudio es ANALÍTICO por que se da a conocer los hechos y fenómenos que se suscitan en una unidad de estudio.

El diseño de investigación es el no experimental, enmarcado en el enfoque mixto predominantemente Cuantitativo, pues cuenta con una variable cualitativa, y dos variables cuantitativas, utilizando hipótesis de investigación multivariables, debido a que cuenta con tres variables que tratan de dar una explicación entre ellos, esto debido a que se partirá estableciendo si se respetó el Debido Procedimiento y se consideraron los principios del derecho administrativo disciplinario que se deben de aplicar en los procesos disciplinario tramitados en la DREP, para luego determinar si se vulneraron derechos de los administrados.

El universo del presente trabajo de investigación esta constituido por los Docentes y Directores de ISP no universitarios es decir por Docentes y Directores de los Institutos Superiores Públicos Pedagogicos, de las Escuelas Superiores de Formación Artística y de los Centro de Educación Técnico Productiva de la Dirección Regional de Educación de Puno que abarca toda la Región de Puno, el mismo que para el año 2014 ascendia a la cantidad de 725 administrados, según el Censo Escolar del Ministerio de Educación del año 2014. También se ha considerado a 06 miembros de la Comisión Permanente de Procesos Administrativos de la DREP, entre titulares y suplentes, y 01 expediente administrativo disciplinario que haya concluido el año 2014.

La muestra estuvo constituida por 30 administrados que representa el $0.4 \%$ de los 725 administrados, 06 miembros de la Comisión Permanente de Procesos Administrativos de la DREP que representa el $100 \%$ del universo y 01 expediente administrativo disciplinario de la Dirección Regional de Educación Puno concluido el año 2014.

El acopio de datos se hizo empleando los siguientes instrumentos: 
Fichas de encuesta, Fichas de observación y Ficha de bibliográfica.

\section{DISCUSIÓN TEÓRICA}

\subsection{La administración pública y su potestad sancionadora}

La Administración Pública "es pues un concepto que engloba al conjunto de organizaciones estatales que realizan la función administrativa del Estado de acuerdo con un ordenamiento jurídico vigente $y$, por su función se pone en contacto directo con la ciudadanía a través de su poder político, satisfaciendo los intereses públicos" (Loyola, 2009, p.05); entendemos entonces que la Administración Pública es toda actividad realizada por el conjunto de entidades que componen el Estado, precisando que este conjunto de entidades está integrado por los funcionarios y servidores públicos, quienes son los encargados de poner en funcionamiento al Estado para el cumplimiento de sus fines y funciones.

El Artículo I del Título Preliminar de la Ley del Procedimiento Administrativo General -Ley No 27444- señala cuales son las entidades integrantes de la Administración Pública, siendo estas: el Poder Ejecutivo, incluyendo Ministerios y Organismos Públicos Descentralizados; el Poder Legislativo; el Poder Judicial; los Gobiernos Regionales; los Gobiernos Locales; los Organismos a los que la Constitución Política del Perú y las leyes confieren autonomía, las demás entidades y organismos, proyectos y programas del Estado, cuyas actividades se realizan en virtud de potestades administrativas $y$, por tanto se consideran sujetas a las normas comunes de derecho público, salvo mandato expreso de ley que las refiera a otro régimen; y las personas jurídicas bajo el régimen privado que prestan servicios públicos o ejercen función administrativa, en virtud de concesión, delegación o autorización del Estado, conforme a la normativa de la materia.

\subsection{La función pública}

Para la consecución de sus fines, el Estado realiza, a través de sus órganos, numerosas actividades que por el destino de las mismas (la sociedad y sus intereses en conjunto), la fuente de la que emanan (el poder estatal), su importancia en la vida nacional y los órganos que la realizan, se denomina: Función Pública.

La Función Pública, como institución de Derecho Público, es una actividad que el ordenamiento jurídico -constitucional y legal-, reserva a los órganos e instituciones del Estado y se manifiesta por la voluntad de los órganos individuales (funcionarios públicos). Toda función pública implica una esfera de atribuciones limitada por el derecho objetivo.

La Ley del Código de Ética de la Función Pública -Ley No 27815-, señala que la función pública es, "toda actividad temporal o permanente, remunerada u honoraria, realizada por una persona en nombre o al servicio de las entidades de la Administración Pública, en cualquiera de sus niveles jerárquicos". 


\subsection{Funcionarios y servidores pu- blicos}

Como se ha referido, la Función Pública es toda actividad que realiza el Estado a través de sus diferentes órganos, concretamente mediante la Administración Pública, la misma que está integrada por los funcionarios públicos, empleados de confianza y servidores públicos.

\subsection{La relación especial de suje- ción}

Los trabajadores que se vinculan con la Administración Pública, a través de un contrato, mantienen una relación jurídica entre ambos la misma que se regirá por los términos y condiciones contenidos en la manifestación bilateral de voluntad que el contrato significa. Sin embargo, también, existe una relación especial del servidor público frente a la Administración el mismo que surge cuando el servidor público es investido de la función pública; al abordar el tema Lizárraga nos explica que:

La relación especial de sujeción es una institución que se refiere a aquellas personas que se encuentran más estrechamente unidas con la Administración, en tanto una vinculación laboral o subordinada, que genera una unión más cercana entre el administrado y el Estado. Proximidad que justifica el ejercicio del poder sancionador disciplinario en virtud de la relación jurídica surgida por la atribución de una función pública, que tiene por finalidad salvaguardar la moralidad y la ética de las relaciones que tienen lugar en el seno de la Administración. (Lizárraga, 2013, p. 56)

\subsection{La responsabilidad de la fun- ción pública}

Al establecerse una relación de empleo entre el servidor público y la Administración Pública, se crea un vínculo jurídico que implica necesariamente deberes y derechos entre ambas partes. Si el servidor público transgrede los primeros, incurre en responsabilidad y se hace acreedor a sanciones, precisa el maestro Salinas Siccha que:

La Administración Pública en un Estado Democrático de Derecho está debidamente organizada por leyes, reglamentos y directivas que deben ser observadas y cumplidas por los funcionarios y servidores en el desempeño de sus actividades y labores al interior de la Administración. El quebrantamiento de aquellas normas, sin duda, acarrea responsabilidad administrativa, civil o dependiendo de la magnitud -hasta penal- por parte del sujeto público. (Salinas, 2011, pp. 4-5)

La transgresión de un deber de la función puede consistir en la violación de las atribuciones o deberes que le impone la titularidad del cargo, o causar un daño patrimonial a la Administración o configurar un delito de carácter penal. A nivel jurídico existen 
pues, tres clases de responsabilidad: la administrativa, la civil y la penal.

\subsection{La potestad sancionadora de la administración pública}

El Estado, como ente jurídico y político, se encuentra dotado de funciones o atributos que le son propios y que se encuentran dirigidos al cumplimiento de determinados fines. Para lograr la realización de sus fines, el Estado tiene la necesidad de actuar $\mathrm{y}$ ejercer determinadas funciones para que sus diversas actividades se puedan cumplir, al margen de las funciones principales del Estado (ejecutivas, legislativas y judiciales), existe una función fundamental común a cada una de ellas: su función sancionadora, que es la llamada a esclarecer la regulación práctica de la libertad y de sus limitaciones, fijando un orden de convivencia a través de reglas de conducta en función del bien común.

Esta función sancionadora es el denominado "Ius puniendi", locución latina que se emplea para referirse a la potestad sancionadora que tiene el Estado "De forma desglosada encontramos por un lado que, la expresión "ius" equivale a decir "derecho", mientras que la expresión "puniendi" equivale a "castigar" y por tanto se puede traducir literalmente como derecho a penar o derecho a sancionar" (Wikipedia.org., s.f.), y así tradicionalmente la doctrina dominante ha venido entendiendo al Ius puniendi como derecho subjetivo, con intervención punitiva del Estado. En cambio, actualmente, algunos autores cuestionan tal naturaleza y pre- fieren hablar de un poder de castigar.

Ahora bien, el Ius puniendi estatal, se manifiesta mediante dos sectores de actuación: el Derecho Penal y el Derecho Administrativo Sancionador, por lo que ambos gozan de una identidad de sustancia y de materia, donde los principios de la potestad sancionadora administrativa tienen base en los principios del Derecho Penal. Ello es así, pues principios como el de legalidad, ne bis in ídem, tipicidad, entre otros, son indudablemente aplicables al ámbito de la potestad sancionadora de la Administración Pública.

El modelo de Estado que postula nuestra sociedad es el de un Estado Constitucional de Derecho, donde:

El ordenamiento jurídico opera como ordenamiento-marco, estableciendo contenidos -tales como la dignidad humana, el reconocimiento de los derechos fundamentales, de la autonomía privada-, así como los fines culturales y sociales del Estado -y procedimientos- tales como el reconocimiento de la Democracia como consecuencia organizativa de la dignidad de la persona, división de poderes, sistema pluripartidista, entre otros. (Del Pozo, 2005, pp. 64-65)

Dentro de este modelo, el Estado dispone de la potestad administrativa disciplinaria como medio para reprimir aquellas conductas consideradas como ilícitos menores o que afecten bienes jurídicos que tienen poca relevancia respecto a los que son tutelados por el Derecho Penal, ya que este se 
rige por el Principio de última ratio, según el cual solo se puede recurrir al Derecho Penal en casos extremos, por lo que antes es necesario agotar otras formas de control social.

Es así que las entidades de la Administración Pública tienen el reconocimiento de una potestad sancionadora específica, que se funda en un imperativo general de coerción, a fin de hacer cumplir los mandatos establecidos en las normas dirigidas a regular y/o determinar las conductas de los administrados frente al Estado. Esta potestad se considera como uno de los poderes más intensos que afectan la esfera de los derechos e intereses de los administrados, toda vez que implica la represión administrativa sobre las conductas infractoras que sean pasibles de producir la imposición de sanciones administrativas conforme a las causales expresamente señaladas en la Ley.

\subsection{El régimen disciplinario en la administración pública}

Las funciones de la Administración Pública, establecen la necesidad de un personal eficiente y calificado, quienes al incumplir sus obligaciones establecidas en leyes o al incurrir en alguna falta administrativa son susceptibles de ser sancionados administrativamente mediante: amonestación, suspensión, cese o destitución del cargo; atendiendo a diversos elementos como la gravedad de la falta, la reincidencia, el daño causado y la intencionalidad con que hayan actuado (sin descartar la posibilidad de incurrir en responsabilidad civil o penal en el ejercicio de sus funciones). En consecuencia los funcionarios y servidores públicos -administrados- se encuentran sometidos a un régimen disciplinario dentro de la misma Administración Pública.

El régimen disciplinario o potestad disciplinaria constituye un instrumento de autotutela que utiliza la Administración Pública para efecto de garantizar y asegurar que la función pública se realice en interés de todos y conforme a los preceptos constitucionales; este régimen se justifica por cuanto el servidor público tiene deberes y obligaciones que trascienden la esfera del interés de la propia Administración como organización, por lo que se busca resguardar su correcto funcionamiento mediante la utilización de instrumentos encaminados a asegurar la disciplina de las personas que lo conforman.

\subsection{Deberes, obligaciones, prohi- biciones e incompatibilidades de los servidores públicos}

Como se ha señalado al funcionario o servidor público se les impone deberes, obligaciones, prohibiciones e incompatibilidades que deben observar, como por ejemplo cumplir con el horario de trabajo, desempeñarse con diligencia, etc., por otro lado el tema de las obligaciones de los funcionarios públicos es el lado inverso de la moneda respecto de sus derechos. Estas situaciones se encuentran establecidas en diversas normas como el Decreto Legislativo No 276 -Ley de bases de la carrera administrativa y de remunera- 
ciones del sector público y su Reglamento, Ley No 27785 -Ley Orgánica del Sistema Nacional de Control y de la Contraloría General de la República, Ley N ${ }^{\circ} 28716$-Ley de Control Interno de las entidades del Estado, Ley No 27588 -Ley que establece prohibiciones e incompatibilidades de funcionarios y servidores públicos, así como de las personas que presten servicios al Estado bajo cualquier modalidad contractual, D. Leg. 933 -Decreto Legislativo que establece sanciones a funcionarios que no cumplen con realizar la declaración y pago de las retenciones y contribuciones sociales, Ley No 27942 -Ley de prevención y sanción del hostigamiento sexual, Ley No 27815 -Ley del Código de Ética de la Función Pública, entre otras normas y sus modificatorias.

\subsection{Faltas y sanciones disciplina- rias}

Se considera falta disciplinaria a toda acción u omisión voluntaria o no, que contravenga las obligaciones, prohibiciones y demás normatividad específica sobre los deberes de los servidores y funcionarios, establecidos en el artículo $28^{\circ}$ de la Ley de bases de la carrera administrativa y de remuneraciones del sector público. La comisión de una falta da lugar a la aplicación de la sanción correspondiente. El artículo $28^{\circ}$ de la Ley de bases, enumera las faltas de carácter disciplinarias que, según su gravedad, pueden ser sancionadas con cese temporal o con destitución, previo proceso disciplinario.

La sanción disciplinaria es la medida disciplinaria que adopta la
Administración Pública contra un trabajador, en relación a la gravedad de la falta que hubiera cometido en el ejercicio de sus funciones. El objetivo que persigue la sanción es la rectificación y cambio de actitud y conducta del servidor infractor.

\subsubsection{Clases de sanción disciplina- ria}

En el ámbito del sector público, los funcionarios y servidores pueden incurrir en responsabilidad administrativa, penalizada con sanciones que van desde una amonestación hasta la destitución del cargo. La Ley de Bases y su Reglamento, han prescrito las sanciones siguientes:

1. Amonestación: Será verbal o escrita. La verbal la efectúa el Jefe inmediato en forma personal y reservada.

2. Suspensión: Es sin goce de remuneraciones y se aplica hasta por un máximo de treinta (30) días.

3. Cese Temporal: Es sin goce de remuneraciones mayor de treinta (30) días y hasta por doce (12) meses. Se aplica previo proceso administrativo disciplinario.

4. Destitución: Es el máximo grado de sanción que se aplica previo proceso administrativo disciplinario.

\subsection{El procedimiento administra- tivo disciplinario}

De acuerdo al Art. 163 y siguientes del Reglamento de la Ley de 
Bases de la Carrera Administrativa, el servidor público que incurra en falta de carácter disciplinario, cuya gravedad pudiera ser causal de cese temporal o destitución, será sometido a procedimiento administrativo disciplinario que no excederá de treinta (30) días hábiles improrrogables. El incumplimiento del plazo señalado configura falta de carácter disciplinario contenida en los incisos a) y d) del Art. 28 de la Ley de Bases de la Carrera Administrativa, Decreto Legislativo $\mathrm{N}^{\circ} 276$.

\subsubsection{Etapas del Proceso Discipli- nario}

La acción administrativa disciplinaria comprende las siguientes etapas:
a) Denuncia
b) Etapa de investigación.
c) Etapa previa al proceso adminis- trativo (calificación por la Co- misión de Procesos Administra- tivos)
d) Etapa del proceso administrativo disciplinario.

\subsubsection{Principales características del Procedimiento Adminis- trativo Disciplinario}

De acuerdo al Artículo 163 del Reglamento del Decreto Legislativo $\mathrm{N}^{\circ} 276$, las principales características son:

a. El Procedimiento Administrativo Disciplinario debe ser escrito y sumario y estará a cargo de una
Comisión de carácter permanente y cuyos integrantes son designados por resolución del titular de la entidad.

b. La Comisión Permanente del Proceso Administrativo Disciplinario deberá estar constituido por tres (3) miembros titulares y tres (3) miembros suplentes.

c. La Comisión Permanente será presidida por un funcionario designado por el titular de la entidad, y la integran además el jefe de personal y un servidor público de carrera, designado por los servidores públicos.

d. Para el procedimiento de funcionarios se constituirá una Comisión Especial integrada por tres miembros acordes con la jerarquía del procesado.

e. La Comisión Permanente del Proceso Administrativo Disciplinario tiene la facultad de calificar las denuncias y quejas que le sean remitidas y pronunciarse sobre la procedencia de abrir o no el Procedimiento Administrativo Disciplinario.

f. El Procedimiento Administrativo Disciplinario será instaurado por resolución del titular de la entidad o del funcionario que tenga la autoridad delegada para tal efecto.

g. Debe notificarse al servidor procesado en forma personal o publicarse en el Diario Oficial "El Peruano" dentro del término de 72 horas, contadas a partir del 
día siguiente de la expedición de la resolución.

h. El servidor procesado tiene derecho a presentar los descargos correspondientes y las pruebas que crea conveniente para su defensa, está será por escrito y tiene un plazo de 5 días hábiles contados a partir del día siguiente de la notificación.

i. El servidor procesado puede hacer su defensa a través de un INFORME ORAL efectuado personalmente o por medio de un apoderado, para lo cual se señalará fecha y hora única.

j. La Comisión Permanente del Proceso Administrativo Disciplinario después de las investigaciones del caso, elevará un INFORME al titular de la entidad, recomendado las sanciones que deban aplicarse al servidor procesado.

k. El servidor procesado podrá ser puesto a disposición de la Oficina de Personal de la entidad, mientras se resuelve su proceso.

1. El Procedimiento Administrativo Disciplinario deberá iniciarse en el plazo no mayor de un año contado a partir del momento en que la autoridad tenga conocimiento de la comisión de la falta disciplinaria; caso contrario se declarará prescrita la acción sin perjuicio del proceso civil o penal a que hubiere lugar.

m. El servidor cesante puede ser sometido a Procedimiento Admi- nistrativo Disciplinario y dentro del plazo de un año a que se refiere el numeral anterior.

n. Los funcionarios y servidores públicos contratados también pueden ser sometidos a Procedimiento Disciplinario dentro del plazo señalado anteriormente.

\subsection{El proceso administrativo dis- ciplinario en la direccion re- gional de educacion puno}

En la Dirección Regional de Educación de Puno coexisten 03 comisiones de procesos disciplinarios.

a) Comisión Especial de Procesos Administrativos Disciplinarios. Esta comisión está facultada para conocer procesos que se siguen contra los Directores de las Unidades de Gestión Educativas -UGEL- y personal jerárquico de la Dirección Regional de Educación, a excepción del Director Regional quien se somete a la Comisión de Procesos Disciplinarios del Gobierno Regional.

b) Comisión Permanente de Procesos Administrativos. Competente para conocer procesos disciplinarios contra docentes y directores de los Institutos Superiores Públicos no universitarios de la Región (Institutos Superiores Públicos Pedagógicos, Escuelas Superiores de Formación Artistica, Centros de Educación Técnico Productiva).

c) Comisión de Procesos Administrativos Disciplinarios. Conoce 
procesos disciplinarios contra el personal administrativo de la misma DREP así como de personal administrativo y de servicios de los Institutos Superiores Públicos no universitarios.

\subsection{El debido proceso y el debido procedimiento}

\subsubsection{Origen y antecedentes del debido proceso}

El derecho a un Debido Proceso es un derecho de muy antigua raigambre y que se ha desarrollado a lo largo de más de siete siglos, el mismo que en la actualidad es considerado como una de las conquistas más importantes que se ha logrado en la lucha por el respeto de los derechos fundamentales de la persona; por lo que se hace necesario, aun de manera escueta, revisar los orígenes remotos del mismo para comprender su verdadero alcance $y$ significado.

El Debido Proceso o "due process of law", como se conoce en la tradición anglosajona, tiene su primera manifestación escrita en la Carta Magna de Inglaterra del año 1215. Posteriormente hubo otras conquistas sobre la arbitrariedad en pos de un juicio justo y equitativo. Así por ejemplo, cabe mencionar la emisión del Acta de Habeas Corpus en 1679 por el Parlamento inglés, la Declaración de Derechos de Virginia en 1776 y la posterior Declaración de Independencia y la Constitución de los Estados Unidos de América en 1788, y luego, la Declaración de los Derechos del Hombre y del Ciudada- no en 1789. Todos estos documentos resultan emblemáticos en la reconstrucción de la historia misma de los derechos fundamentales, incluido por supuesto el derecho a un Debido Proceso. Pero antes de la consagración definitiva de este derecho en las Constituciones de los Estados y posteriormente en los tratados internacionales de derechos humanos, es necesario hacer alusión al desarrollo que experimentó este derecho en el seno de la Constitución estadounidense.

\subsubsection{Concepto del debido proceso}

$\mathrm{Al}$ abordar el estudio del Debido Proceso podemos encontrar una variedad de conceptos desarrollados por la doctrina nacional y extranjera, entre ellos Quiroga, señala que "constituye un concepto moderno íntimamente referido a la validez y legitimidad de un proceso judicial, concepto extendido al funcionamiento de todo el aparato estatal, no limitado a una materia específica, teniendo su raíz y fundamento en el proceso judicial jurisdiccional”. (Quiroga, 2014, p. 76)

De Bernardis, citado por Ticona, sostiene que el Debido Proceso es una garantía y un derecho fundamental de todos los justiciables que les permitirá, una vez ejercitado el derecho de acción, puedan, efectivamente, acceder a un proceso que reúna los requisitos mínimos que lleven a la autoridad encargada de resolverlo a pronunciarse de manera justa, equitativa e imparcial. Es decir, aquellos elementos mínimos que resultan exi- 
gibles por los justiciables para que el proceso que se desarrolle -cualquiera que este sea- pueda permitirle acceder a la cuota mínima de justicia a la que este debe llevarle. De esta manera, el proceso se constituirá en el vehículo que proporciona y asegura a los justiciables el acceso a la justicia, entendida esta como valor fundamental de la vida en sociedad. (Ticona, 1999, p. 138)

El Debido Proceso no solo se circunscribe en las garantías del Proceso, pues tiene una fundamentación axiológica, "Veamos pues como nos encontramos ante un concepto cuyos alcances no solamente se limitan a un escenario jurisdiccional, sino que son alegables tanto en un ámbito administrativo como incluso en relaciones corporativas entre particulares $y$, además, que no se limita al mero cumplimiento de ciertas pausas sino que está internamente ligado a la consecuencia del valor justicia...". (Espinosa-Saldaก๊a, 2003, p. 416)

Por nuestra parte, tratando de ensayar una breve definición, podemos sostener que el Debido Proceso es una garantía constitucional por la cual se protege a las personas frente al Estado cuando se abordan derechos o situaciones jurídicas de estos, el cual se debe regir por un procedimiento legal donde se garantice su defensa ante un juez o tribunal competente, independiente e imparcial y dentro de un plazo razonable en la sustanciación de cualquier proceso civil, penal, laboral, constitucional, administrativo o de cualquier otro aspecto.

\subsection{El debido proceso en sede ad- ministrativa (debido procedi- miento)}

La Administración Pública no se encuentra exenta de cumplir con todas las garantías que permitan alcanzar una decisión justa en los procedimientos administrativos de su competencia, más aún si se tiene en cuenta que la administración se encuentra vinculada a la Constitución Política, por lo que debe respetar sus principios, tales como el Debido Proceso y velar por el cumplimiento de sus fines, entre los que se encuentra la protección de los derechos de la persona y su dignidad.

Es así que el principio del Debido Proceso, entendido como el conjunto de garantías que permiten que las personas puedan tener un proceso regular y justo, se expande al ámbito de los procedimientos administrativos como el Principio del Debido Procedimiento. Esta cobertura se da porque los operadores del sistema constitucional y, en particular los jueces, van delineando verdaderas reglas jurídicas, vigentes para el ámbito administrativo que van construyendo sus propias pautas a partir de normas inferidas o deducidas de algunos artículos constitucionales de tipo amplio, como por ejemplo, las que regulan el Debido Proceso. En esa línea, el Tribunal Constitucional considera que el derecho al Debido Proceso reconocido en el numeral 3 del Artículo $139^{\circ}$ de la Constitución Política del Perú, no solo tiene una dimensión estrictamente jurisdiccional, sino que se extiende también al procedimiento administrativo. 
El fundamento principal por el que se habla de un Debido Proceso administrativo encuentra sustento en el hecho de que tanto la administración como la jurisdicción están indiscutiblemente vinculadas a la Carta Magna, de modo que si ésta resuelve sobre asuntos de interés del administrado, y lo hace mediante procedimientos internos, no existe razón alguna para desconocer las categorías invocables ante el órgano jurisdiccional. (Sentencia recaida en el Expediente $\mathrm{N}^{\circ} 8495$ 2006-PA/TC, 2006)

\subsection{Garantías del debido procedi- miento administrativo}

A continuación desarrollamos el contenido de los derechos y las garantías que conforman el Debido procedimiento administrativo, en algunos casos se ha recurrido a la jurisprudencia más relevante emitida por nuestro Tribunal Constitucional.

a) Derecho a la notificación

b) Derecho de acceso al expediente

c) Derecho a la defensa

d) Derecho a ofrecer $y$ producir pruebas

e) Derecho a una decisión motivada y fundada en derecho

f) Derecho a la presunción de licitud

g) Derecho al plazo razonable

h) Derecho a ser investigado por una autoridad competente

i) Derecho a ser investigado por una autoridad imparcial j) Derecho a impugnar las decisiones administrativas

k) Ne bis in idem

1) Principio de publicidad de normas procedimentales

\subsection{Principios del procedimiento administrativo disciplinario}

Una aproximación conceptual sobre los principios del derecho nos dice que "son verdades primeras y básicas, que sirven de punto de apoyo para todo raciocinio siendo evidentes por sí mismos. Los mismos tienen una función fundamental en derecho por que, en primer lugar, son los que ilustran en el supuesto de inexistencia u oscuridad de las normas y, en segundo lugar, todo excepción a un principio general debe efectuarse por texto expreso y es de aplicación estricta" (Flores, R., s.f.).

En tal sentido, en el ámbito de los procedimientos disciplinarios, consideramos que, a la par de la aplicación de las normas que rigen al Debido Proceso en el ámbito del procedimiento administrativo, serán de aplicación aquellas garantías y principios del derecho de defensa en el orden penal, es decir, aquellos derechos del Debido Proceso jurisdiccional aplicables al ámbito penal (con las peculiaridades debidas), en ese sentido el Tribunal Constitucional peruano, ha señalado: "No obstante la existencia de estas diferencias, existen puntos en común, pero tal vez el más importante sea el de que los principios generales del derecho penal son de recibo, con ciertos matices, en el derecho admi- 
nistrativo sancionador" (Sentencia recaida en el Expediente $\mathrm{N}^{\circ} 1873-2009$ PA/TC, 2010).

Entre algunos Principios sustanciales podemos señalar los siguientes:
a) Legalidad
b) Tipicidad
c) Debido Proceso o Debido Pro- cedimiento
d) Razonabilidad y Proporcionali- dad.
e) Imparcialidad.
f) Presunción de licitud
g) Principio de inmediatez

\subsection{Derechos de los administrados}

En el ejercicio del ius puniendi el Estado debe respetar los derechos fundamentales y derechos humanos, establecidos en la Constitución (extensivamente por los Tratados reconocidos por nuestro país); y esto por la sencilla razón, de que el Estado peruano al igual que la Sociedad, tienen el deber de proteger los derechos fundamentales, a tenor del art. $1^{\circ}$ de nuestra Constitución, y por tanto, el Estado al ejercer su potestad sancionadora, no puede desconocer tales derechos, bajo sanción de que el proceso sea declarado nulo.

No preocupa..., el hecho de que la Administración tenga poder, sino que lo emplee fuera de los cauces de la legalidad, lo que constituiría abuso de poder y arbitrariedad. Pero, aun cuando la Constitución y el ordenamiento jurídico son las pautas básicas para la correcta actuación de la Administración, no la libran de errores. Por ello se ha instaurado el control judicial de la Administración Pública. De esta manera, el Poder Judicialrepresenta la instancia adicional revisora y correctora de los vicios e irregularidades que en vía administrativa se hayan podido cometer mediante el proceso Contencioso-Administrativo. (Defensoria del Pueblo, 2007)

En efecto el art. $148^{\circ}$ de la Constitución Política regula el proceso contencioso administrativo, consagrándolo como un mecanismo para el control judicial de la legalidad de la actividad de la Administración Pública, mediante el cual los ciudadanos pueden acudir ante el Poder Judicial cuestionando las decisiones administrativas que los afecten, siendo el fin del proceso contencioso administrativo actuar como una garantía esencial del Estado de Derecho, porque constituye un mecanismo creado para controlar que la Administración Pública actúe subordinada al marco jurídico que regula su actividad (la Constitución, las leyes y los reglamentos), permitiendo a los ciudadanos acudir a otro Poder del Estado (el Judicial) demandando que evalúe si las actuaciones de la Administración son contrarias o no a Derecho.

$$
\text { El artículo } 1^{\circ} \text { del Texto Único }
$$
Ordenado de la Ley No 27584 prescribe que el proceso Contencioso Administrativo tiene por finalidad el control jurídico por el Poder Judicial de las actuaciones de la Administración Pública sujetas al derecho 
administrativo y la efectiva tutela de los derechos e intereses de los administrados, se debe precisar que “... se considera que el proceso Contencioso Administrativo posee una doble naturaleza. Es objetivo, en tanto se dirige a tutelar la legalidad de las actuaciones administrativas, pero también es subjetivo, en tanto protege a los administrados ante el comportamiento arbitrario de la autoridad administrativa". (Guzmán, C., s.f.)

La Ley del Proceso Contencioso Administrativo, -Ley No 27584- en su Art $3^{\circ}$, al referirse a la exclusividad del proceso contencioso administrativo, dice que "las actuaciones de la administración pública sólo pueden ser impugnadas en el proceso contencioso administrativo, salvo los casos en que se pueda recurrir a los procesos constitucionales". Es así que, ante la violación o posible violación a un derecho fundamental en un procedimiento administrativo, donde también se incluye a los procesos administrativos disciplinarios, es viable que también se pueda acudir a una acción de amparo.

\subsection{La acción de amparo}

La defensa de los derechos fundamentales distintos a la libertad personal -tutelable por el habeas corpus- $\mathrm{y}$ los derechos al acceso a la información y la identidad informativa -protegidos por el habeas data-, constituyen residualmente el catálogo de derechos a ser tutelados mediante el amparo.

En efecto, "el Proceso Constitucional de Amparo tiene como finalidad esencial la protección efectiva de los derechos constitucionales, reponiendo las cosas al estado anterior a la violación o amenaza de violación de un derecho constitucional, o disponiendo el cumplimiento de un mandato legal o de un acto administrativo” (Velásquez, R., 2013)

De esta manera, el artículo 200, inciso 2, de la Constitución establece una vía de tutela urgente ante transgresiones a derechos fundamentales, que en el ámbito de la Administración Pública generalmente se dan ante circunstancias que requieren una tutela jurisdiccional urgentísima y perentoria.

Dentro de una óptica constitucionalista se podría sostener que: los procedimientos administrativos, para que sean válidos, deben respetar los derechos fundamentales de los administrados. En ese entendido, las garantías del Debido Procedimiento son exigibles de manera general por los administrados a condición que los procedimientos administrativos así lo permitan, según la interpretación del juez constitucional. De modo que el derecho de defensa, la "jurisdicción" predeterminada por la ley, la pluralidad de instancia, la cosa decidida, entre otras garantías constituyen atributos que la Administración Pública no debe vulnerar en los procedimientos a su cargo. Así, lo ha reconocido el Tribunal Constitucional, cuando senala que la potestad sancionatoria de la administración debe asegurar con sus matices propios los principios del orden penal, como el derecho de defensa, competencia y procedimiento, 
proporcionalidad y razonabilidad de las sanciones.

Con ello se verifica que el Estado es el responsable de mantener la vigencia de los derechos fundamentales y con el fin de hacer efectivos los derechos e intereses de los administrados ha previsto una serie de mecanismos o garantías institucionales de carácter procesal.

\subsection{El régimen disciplinario en la ley de servicio civil}

El proceso administrativo disciplinario en el marco del D. Leg. 276 y su reglamento Decreto Supremo ${ }^{\circ}$ 005.90.PCM fue sustituido por el régimen sancionador previsto en la Ley No 30057 Ley de Servicio Civil y su reglamento aprobado por el Decreto Supremo $N^{\circ}$ 040.2014.PCM a partir del 14 de Setiembre del 2014 y las normas sobre el Proceso Administrativo Disciplinario regulada por el D. Leg. 276 y su reglamento seguirán vigentes para faltas administrativas cometidas hasta el 13 de Setiembre del 2014 y para casos que vinieran conociendo las CPPAD y CEPAD hasta que las mismas culminen con su trámite, ante lo cual las comisiones se desactivaran. Si bien esta el proceso administrativo disciplinario normado en el $\mathrm{D}$. Leg. 276 ha sido derogado, es considerado como base sólida para comprender y aplicar el nuevo régimen disciplinario bajo la ley Servir.

Puntualmente sobre el régimen disciplinario en la Ley Servir podemos señalar que son mas garantistas, específicas y sistemáticamente ordenadas que el D. Leg. 276 y su reglamento, pues ya no será necesario remitirse a otras normas para su comprensión, como cuando se refería a "autoridad competente" no logrando comprenderse quien era la persona que califica y aplica la sanción, ahora se especifica que el órgano sancionador el Jefe inmediato, siendo este la primera instancia para imponer sanciones de amonestación, en el caso de sanciones de suspención lo es el jefe de Recursos Humanos y para las destituciones el titular de la entidad, siendo el Tribunal del Servicio Civil la segunda instancia.

El órgano instructor contará con la asistencia de una Secretaria Técnica integrada de preferencia por abogados designados en tal función como añadidura a otras, consideramos que este es un buen acierto, pues ahora si se contara con la capacidad profesional de los abogados, quienes tendran una oportunidad de labor especializada en dicha área.

Se hace necesario la capacitación sobre el nuevo régimen sancionador a los Jefes inmediatos, Jefes de Recursos Humanos y titulares de las entidades de la Administración Pública, las misma que ayudarán a salir de dudas o temores por desconocimiento a actuar frente a presuntas faltas administrativas. Los Jefes inmediatos deben tener claramente delimitado los servidores sobre quienes tienen competencia sancionadora, a fin de evitar infundadas cuestiones de compentencia $u$ otras dilaciones innecesarias.

Con la nueva ley Servir desaparecen las Comisiones Permanentes de 
Procesos Administrativos Disciplinarios y a la vez desaparecen también los representantes de los trabajadores, quienes muchas veces actuaban como defensores del trabajador procesado, confundiendo su rol de defensor del Debido Procedimiento Administrativo.

Por último se debe precisar que las normas sobre el Proceso Administrativo Disciplinario regulada por el D. Leg. 276 y su reglamento seguiran vigentes solo para casos que vinieran conociendo las CPPAD y CEPAD hasta que las mismas culminen con su trámite, ante lo cual se desactivaran.

\section{RESULTADOS DE LA INVESTIGACIÓN}

El propósito de la investigación sobre el estudio del Debido Procedimiento en los procesos administrativos disciplinarios respecto a los derechos de los Docentes y Directores de ISP no universitarios (administrados) de la Dirección Regional de Educación en el año 2014, pretende determinar si en los procesos disciplinarios se respetó el Debido Procedimiento así como si se consideraron los principios del Derecho Administrativo Disciplinario, tanto en el procedimiento como en las decisiones finales, para ello, de acuerdo a la información obtenida y conforme a las técnicas e instrumentos utilizados, se ha llegado a importantes resultados.

\subsection{Análisis e interpretación de los cuestionarios}

En lo que respecta a cuestionarios se ha aplicado el procesamiento estadístico elemental, calculando frecuencias de respuesta y porcentajes que representan estas. Entendemos que la intención de estos cuestionarios tienen un carácter exploratorio de los fenómenos resaltantes de la investigación, se presentan los datos agrupados en las categorías de análisis fundamentales de cada instrumento y se presenta un análisis breve de las ideas más relevantes que sugieren las mismas. Más que emitir juicios de valor sobre el resultado de estos cuestionarios, queremos presentar la realidad que se manifiesta en la Comisión Permanente de Procesos Administrativos de la DREP, desde la óptica de los administrados y de los propios miembros de esta Comisión. A continuación se presentan los resultados mas resaltantes:

a) Para conocer que irregularidades o defectos consideraron como los más grave en las investigaciones disciplinarias realizadas por la CPPA de la DREP se ha formulado la siguiente interrogante: ¡cuales de las deficiencias, que considere mas grave, ha observado en el trámite de los procedimientos disciplinarios?, obteniéndose el siguiente resultado: 


\section{TABLA No 01: DEFICIENCIAS OBSERVADAS POR LOS ADMINISTRADOS EN EL TRAMITE DE LOS PROCEDIMIENTOS DISCIPLINARIOS (SOLO POR QUIENES CONOCIERON O FUERON SOMETIDOS A PROCESO DISCIPLINARIO)}

\begin{tabular}{|c|l|c|c|}
\hline Item & \multicolumn{1}{|c|}{ CATEGORÍAS } & $\mathbf{f}_{i}$ & $\%$ \\
\hline 1 & $\begin{array}{l}\text { No se permitió ejercer el derecho de defensa de forma } \\
\text { adecuada y restringieron la obtención de copias del ex- } \\
\text { pediente }\end{array}$ & 1 & $7 \%$ \\
\hline 2 & $\begin{array}{l}\text { No investigaron de forma eficiente, pues se sancionó sin } \\
\text { pruebas o no valoraron las pruebas ofrecidas por los in- } \\
\text { vestigados }\end{array}$ & 4 & $27 \%$ \\
\hline 3 & $\begin{array}{l}\text { No respetaron los plazos de investigación y se excedieron } \\
\text { en los mismos }\end{array}$ & 7 & $46 \%$ \\
\hline 4 & $\begin{array}{l}\text { Los miembros de la Comisión no fueron neutrales ni im- } \\
\text { parciales }\end{array}$ & 0 & $0 \%$ \\
\hline 5 & $\begin{array}{l}\text { La Resolución de sanción no fue proporcional para la falta } \\
\text { cometida y no estaba bien motivada }\end{array}$ & 2 & $13 \%$ \\
\hline 6 & $\begin{array}{l}\text { No se cumplió con notificar de forma adecuada ni opor- } \\
\text { tuna }\end{array}$ & 1 & $7 \%$ \\
\hline & TOTAL & 15 & $100 \%$ \\
\hline
\end{tabular}

Fuente: Encuesta aplicada a 15 administrados de la DREP Elaboración: El Autor.

Los resultados obtenidos en este ítem indican que casi un 50\% de los administrados refieren que no se respetaron los plazos de investigación, ninguno de los encuestados señalo que los miembros de la Comisión no fueron neutrales ni imparciales; se debe recordar que la pregunta busca saber cuál es la mayor irregularidad observada por los encuestados, siendo esta el que no se cumplió con los plazos de investigación establecidos en la Ley y en menor grado otras observaciones que advirtieron en los procesos disciplinarios. b) Con la finalidad de indagar sobre el nivel de conocimientos que tienen los miembros de la CPPA sobre el Proceso Disciplinario, Principios del Derecho Administrativo Disciplinario y el Debido Procedimiento Administrativo se ha realizado un serie de proposiciones verdaderas y falsas para que los encuestados respondan si la consideran Verdaderas o Falsas, donde encontramos los resultados que a continuación se detallan: 


\section{GRÁFICO No 01: GUÍA DE ENCUESTA DIRIGIDO A LOS MIEMBROS DE LA CPPA DE LA DREP SOBRE EL DEBIDO PROCEDIMIENTO}

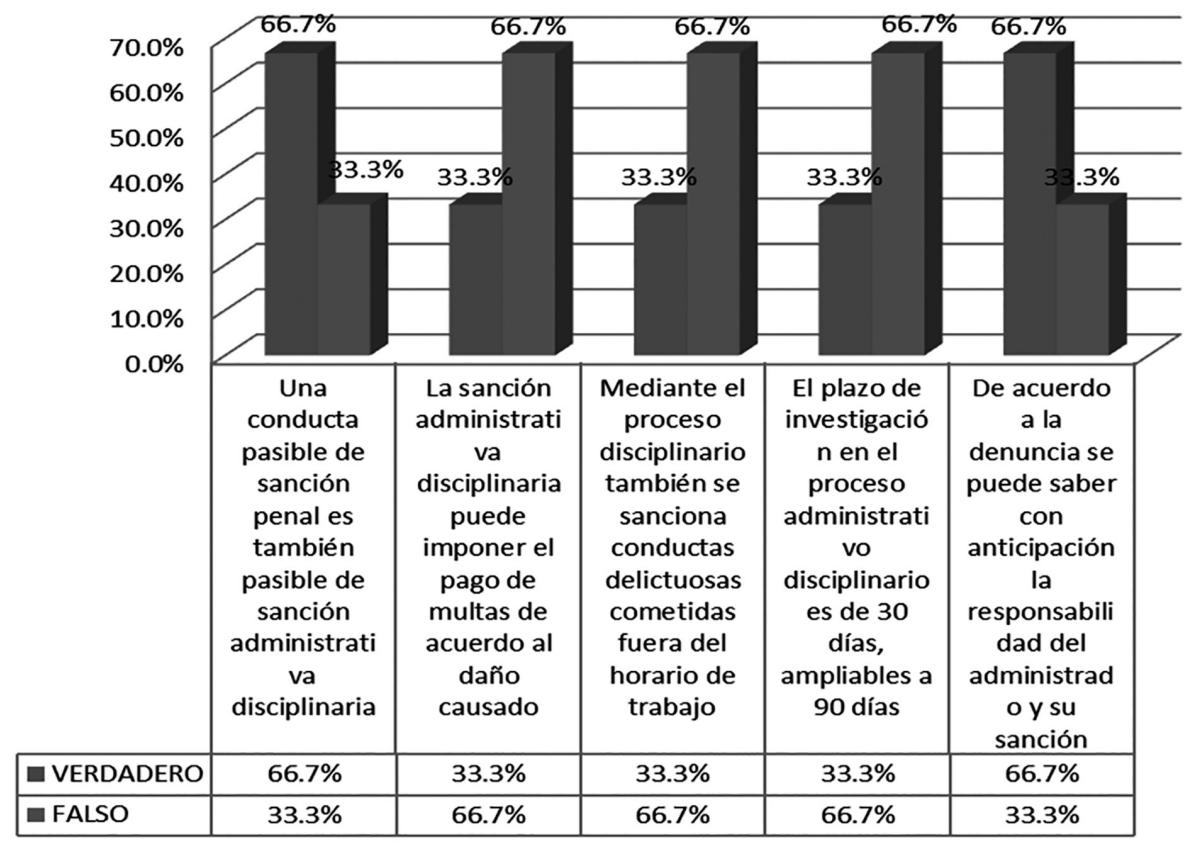

Fuente: Encuesta aplicada a 06 miembros de la CPPA de la DREP Elaboración: El Autor.

De los criterios sobre el Proceso Disciplinario y el Debido Procedimiento Administrativo que tienen los miembros de la Comisión Permanente de Procesos Administrativos Disciplinarios, se tiene como resultado un relativo conocimiento del Proceso Disciplinario, de los principios del proceso disciplinario y del Debido Procedimiento administrativo, pues en casos en que sus respuestas debieran ser consideradas como afirmaciones falsas algunos miembros responden como verdaderas y en los casos en que las respuestas deben ser consideradas como proposiciones verdaderas, los entrevistados, respondieron como falsas.

\section{OBSERVACIONES Y DEFECTOS ENCONTRADOS EN EL EXPEDI- ENTE ADMINISTRATIVO DIS- CIPLINARIO:}

A continuación, se muestran los resultados más resaltantes del análisis de un expediente administrativo disciplinario tramitado por la Comisión Permanente de Procesos Disciplinarios de la DREP.

I. UNIDAD DE ESTUDIO: Expediente Administrativo Disciplinario S/N del año 2012 


\section{DATOS GENERALES DEL EXPEDIENTE}

1. Cargo que desempeñan los administrados investigados:

a) Investigado 1: Presidente del Comité de Mantenimiento 2009.

b) Investigado 2: Miembro del Comité de Mantenimiento 2009.

c) Investigado 3: Miembro del Comité de Mantenimiento 2009.

2. Fecha de denuncia: 18 de Abril del 2011-Informe $\mathrm{N}^{\circ}$ 001-2011-ME-DREP/OCI-EEPMPLE.2009.

3. Fecha de inicio de procedimiento: 13 de Abril del 2012 - Resolución No 0527-2012-DREP.

4. Fecha de conclusión: 19 de Mayo del 2014-Resolución $\mathrm{N}^{\circ}$ 1210-2014-DREP

En principio las notificaciones a los docentes investigados con los cargos imputados no se hicieron en el plazo establecido en la Ley, las mismas se efectuaron luego de transcurrido más de 18 meses.

Respecto al desarrollo del procedimiento disciplinario, se evidencia que los principios de impulso de oficio y verdad material que rigen el procedimiento administrativo, la Comisión debió realizar las diligencias necesarias a fin de corroborar la veracidad de los hechos investigados y llegar a las conclusiones arribadas en el Informe $\mathrm{N}^{\circ}$ 001-2011-ME-DREP/ OCI-EE-PMPLE.2009.

En el presente caso no se tiene la actuación de medios probatorios que acrediten la comisión de los hechos investigados por los administrados, esto se debe a que la Comisión Permanente de Procesos Administrativos de la DREP no realizó las diligencias necesarias para ello; por el contrario, solo valoró el Informe del Órgano de Control Institucional de la DREP, no ha actuado otras pruebas (incorporadas al proceso de oficio o a pedido de parte) para comprobar los hechos investigados, así como tampoco valoró los argumentos expresados por los investigados en sus escritos de descargos. De esta forma, ha quedado acreditado que mediante la Resolución Directoral Regional No 1210-2014-DREP se ha impuesto una sanción a los administrados sin haberse realizado las diligencias suficientes.

Además, se observa que los escritos de descargo y otros no tiene pronunciamiento en el plazo legal y solo tiene respuesta en la Resolución final donde la Comisión, sin mayor análisis, resolvió sancionar a los administrados; acreditándose de esta manera una indebida motivación.

Existe una restricción o limitación al derecho de defensa, pues el expediente disciplinario no contiene todo lo actuado por el Órgano de Control Institucional el cual al emitir su informe cono resultado de las acciones de control, constituye prueba pre constituida para el inicio (de ser el caso) de procesos administrativos. 
Se ha impuesto como sanción disciplinaria la suspensión temporal para el ejercicio de sus funciones por el lapso de dos meses, la misma que no esta prevista en el Dec. Supremo 00590-PCM, esta imposición de sanción genera duda o está sujeta a interpretación sobre sus alcances; por lo que se encuentra obviamente reñido con el debido procedimiento administrativo y por tanto estaríamos ante un acto administrativo viciado.

Respecto al principio de inmediatez, debemos indicar que una ausencia de regulación, en el marco de un procedimiento administrativo disciplinario, no equivale a que la Administración aplique las sanciones correspondientes en plazos excesivos e irrazonables; el transcurso injustificado de un tiempo excesivo entre la toma de conocimiento de la falta cometida y la imposición de la sanción, se asemeja a la decisión tácita del empleador de condonar dicha falta $o$ simplemente de no sancionar al trabajador que la cometió.

En el presente caso la CPPA tomo conocimiento de las presuntas faltas de los administrados es en fecha 18 de Abril del año 2011 y la emisión de la Resolución por la cual se instaura proceso administrativo y se imputa a los investigados la comisión de presuntas faltas es de fecha 13 de Abril del año 2012, excede el plazo razonable que tenía la Comisión para determinar el inicio o no de un procedimiento de investigación disciplinaria, finalmente la Resolución que impone sanción disciplinaria a los investiga- dos es emitida en fecha 19 de Mayo del año 2014. Se tiene entonces que la presente investigación disciplinaria a excedido en demasía los plazos de investigación, teniendo en cuenta que los hechos investigados no tuvieron un grado de complejidad que justifique su dilación.

En tal sentido, consideramos que en el procedimiento disciplinario analizado se han vulnerado los principios de impulso de oficio, verdad material, debido procedimiento, principio de inmediatez y plazo razonable en perjuicio de los derechos de los administrados.

\section{CONCLUSIONES}

1. Conforme nuestro objetivo planteado, la presente investigación nos a permitido demostrar que en los procesos administrativos disciplinarios realizados por la CPPA de la DREP concluidos el año 2014, no se respetó el Debido Procedimiento y tampoco se consideraron los principios del Derecho Administrativo Disciplinario; el expediente disciplinario analizado se encuentran con afectación de derechos constitucionales de los administrados, debido a la escasa preparación que tienen los miembros que conforman la CPPA, lo cual ha sido percibido por los propios administrados.

2. La CPPA de la DREP esta conformado por cinco profesionales distintos al de la Abogacia, quienes no tienen una formación en Derecho, que no solo correspon- 
de al estudio de la ley, sino de los principios, bases y fundamentos que fijan orientaciones para la determinación del contenido del Derecho y su interpretación (sentido y alcances). Esta conformación no garantiza a los administrados que se imparta una correcta justicia administrativa pues se ha observado que en la tramitación de los procesos disciplinarios existen serias deficiencias y un desconocimiento sobre el contenido del Debido Procedimiento y de los principios del Derecho Administrativo Disciplinario.

3. En los procesos disciplinarios tramitados por la Comisión Permanente de Procesos Administrativos de la DREP se han advertido problemas de lentitud y dilaciones en los procedimientos disciplinarios, lo cual refleja la escasa efectividad a la hora de dilucidar las responsabilidades e imponer sanciones dentro de los plazos establecidos en la normativa correspondiente, lo que no sólo no permite desincentivar la comisión de faltas administrativas sino que también originan en la ciudadanía una sensación de impunidad y en algunos casos la prescripción de la acción disciplinaria y por ende la impunidad de los infractores.

4. En la tramitación de los procesos disciplinarios se ha observado una omisión de contemplar los principios del derecho ad- ministrativo disciplinario y solo limitarse a los ya establecidos en la Ley 27444 , lo que no es compatible con lo normado en nuestra ley de leyes, por lo que se afecta al Debido Procedimiento, principios constitucionales $\mathrm{y}$ derechos consagrados constitucionalmente que asiste a todo administrado; además los administrados se encuentran disconformes de la forma como se llevan los procesos administrativos disciplinarios tramitados por la CPPA, considerando que no se observaron los plazos legales, no se impulsó de oficio la investigación, los escritos no se prevén en el plazo de ley, entre otros.

\section{BIBLIOGRAFÍA}

1. Defensoría del Pueblo. (2007). Propuesta para una reforma de la Justicia Contencioso-Administrativa desde la perspectiva del acceso a la justicia -Informe Defensorial No 121-. Lima. Defensoría del Pueblo.

2. Del Pozo, C. (2005). Control Difuso y Procedimiento Administrativo. Lima: Palestra Editores S.A.C.

3. Espinosa-Saldaña Barrera, E. (2003). Jurisdicción Constitucional Importación de Justicia y Debido Proceso. Lima: ARA Editores.

4. Flores Dapkevicius, R. (s.f.). $E l$ Procedimiento Administrativo Común. Recuperado de http:// 
www.monografias.com/trabajos24/procedimiento-administrativo/ procedimiento-administrativo.shtml

5. Fundación Wikimedia. Ius puniendi. Recuperado de https:// es.wikipedia.org/wiki/Ius_puniendi

6. Guzmán Napurí, C. (s.f.). Las actuaciones impugnables en el Proceso Contencioso Administrativo peruano. Recuperado de http://revistas.pucp. edu.pe/index.php/derechoadministrativo/ article/viewFile/13549/14174

7. Lizárraga Guerra, V. (2013). El Derecho Disciplinario. Lima: Grijley.

8. Quiroga León, A. (2013). El Debido Proceso Legal en el Perú. Recuperado de http://blog. pucp.edu.pe/blog/ariojabermudez/2013/05/25/el-debido-proceso-legal-en-el-per/

9. Rojas, Vargas, F. (2012). Derecho Penal Práctico Procesal y
Disciplinario. Lima: Gaceta Jurídica.

10. Salinas Siccha, R. (2011). Delitos contra la Administración Pública. Lima: Grijley.

11. Ticona Postigo, V. (1999). El Debido Proceso y la Demanda Civil. Lima: Rodhas.

12. Velásquez Ramírez, R. (2013),. Proceso de Amparo. Recuperado de http://blog.pucp. edu.pe/blog/ariojabermudez/2013/03/22/proceso-deamparo/

13. Villa Stein, J. (1998). Derecho Penal Parte General. Lima: San Marcos.

\section{Jurisprudencia}

14. Perú. Tribunal Constitucional. Sentencia emitida en el Expediente $\mathrm{N}^{\circ}$ 8495-2006- PA/ TC, el 07 de Agosto del 2008.

15. Perú. Tribunal Constitucional. Sentencia emitida en el Expediente $\mathrm{N}^{\circ}$ 1873-2009-PA/TC, el 03 de Setiembre del 2010. 